\title{
IDENTIFIKASI PRASYARAT TRANSFORMASI SISTEM MANAJEMEN RISET PERGURUAN TINGGI INDONESIA MENUJU WORLD CLASS UNIVERSITY
}

\author{
IDENTIFICATION OF ENABLING FACTORS FOR TRANSFORMATION OF INDONESIAN HIGHER \\ EDUCATION INSTITUTION'S RESEARCH MANAGEMENT SYSTEM TOWARD WORLD CLASS UNIVERSITY
}

\author{
Yuli Sukmawati ${ }^{* 1}$, Anas Miftah Fauzi**) dan Hari Wijayanto***) \\ *) SEAFAST CENTER, LPPM-IPB University \\ Jl. Ulin No. 1 Gedung SEAFAST Center, Kampus IPB, Dramaga, Bogor, 16680, Indonesia \\ ${ }^{* *}$ Departemen Teknologi Industri Pertanian, Fakultas Teknologi Pertanian, IPB University \\ Gedung Fateta Lantai 2, Kampus IPB Dramaga, Bogor 16680, Indonesia \\ ${ }^{* * *}$ Departemen Statistik, Fakultas Matematika dan Ilmu Pengetahuan Alam, IPB University \\ Jl. Meranti Wing 22 Level 4, Kampus IPB Darmaga, Bogor 16680, Indonesia
}

\begin{abstract}
This research was conducted to identify enabling factors for an effective transformation of Higher Education Institution's (HEI's) research management system in Indonesia towards World Class University (WCU) status. Three clusters of HEIs, particularly PTN-bh WCU, PTN-bh and PTN Non-bh produced exceptional studies output and outcome (citation) wherein PTN-bh WCU produced the best quantity of publications and citations. The data analysis technique in this study used a comparative analysis of research mapping and Biplot analysis. The result of the Biplot analysis indicate that research infrastructure as essential enabler for all HEIs. Biplot also displays the important enabler that affected research productivity in PTN Non-bh (research human resources, academic collaboration), PTN-bh (research funding, insentive, PTN-bh WCU (academic culture, system and management research).
\end{abstract}

Keywords: research management system, enabler factors, transformation, world class university, Biplot analysis

\begin{abstract}
Abstrak: Penelitian bertujuan mengidentifikasi prasyarat transformasi sistem manajemen riset yang efektif pada perguruan tinggi di Indonesia untuk menuju status World Class University (WCU). Responden terdiri dari tiga klaster perguruan tinggi yaitu PTN-bh WCU, PTN-bh, dan PTN Non-bh. Ketiga klaster responden menghasilkan luaran penelitian (jumlah publikasi dan sitasi) yang berbeda, dan PTN-bh WCU menghasilkan jumlah publikasi dan sitasi tertinggi. Teknik analisis data dalam penelitian ini menggunakan analisis komparasi pemetaan riset dan analisis Biplot. Hasil analisis biplot mempertegas infrastruktur riset sebagai prasyarat utama bagi semua perguruan tinggi. Prasyarat penting yang secara spesifik memengaruhi kinerja riset juga ditunjukkan oleh hasil Biplot, yaitu PTN Non-bh (SDM riset, kerjasama akademik), PTN-bh (pendanaan riset, insentif) dan PTN-bh WCU (budaya akademik, sistem dan manajemen riset).
\end{abstract}

Kata kunci: sistem manajemen riset, prasyarat tranformasi utama, prasyarat tranformasi penting, prasyarat tranformasi penunjang, world class university, analisis biplot

\footnotetext{
${ }^{1}$ Corresponding author:

Email: yulisukmawati@apps.ipb.ac.id
} 


\section{PENDAHULUAN}

Pemeringkatan mempunyai dampak sangat besar tidak hanya sangat penting untuk menarik calon mahasiswa namun untuk institusi itu sendiri. Peringkat membantu membangun dan mempertahankan reputasi. Institusi pendidikan tinggi mengubah kebijakan dan strategi untuk meningkatkan posisi mereka di peringkat global. Selain itu, upaya yang dilakukan misalnya dengan merekrut peraih Nobel untuk meningkatkan capaian indikator kinerja risetnya (Jarocka, 2015). Pendidikan Tinggi di Indonesia telah mengalami banyak perubahan dalam beberapa tahun terakhir ini. Era globalisasi dan revolusi 4.0 saat ini juga turut menyumbang perubahan dalam sistem penyelenggaraan pendidikan tinggi di Indonesia. Perubahan ini merupakan salah satu respon atas adanya tuntutan untuk melakukan perubahan dari sisi internal dan eksternal (Tambunan dan Anwar, 2019). Tren publikasi internasional para peneliti Indonesia khususnya dari perguruan tinggi pada tahun 2014-2018 terus mengalami kenaikan, publikasi internasional Indonesia pada tahun 2018 hanya berbeda sedikit dengan Malaysia (Kemenristekdikti, 2019). Pada tahun 2019, 11 Perguruan Tinggi Negeri berbadan Hukum (PTN-bh) Indonesia ditargetkan oleh Kementerian Riset, Teknologi dan Pendidikan Tinggi masuk ke dalam peringkat 500 besar dunia. Menteri Riset, Teknologi dan Pendidikan Tinggi telah memiliki strategi untuk memacu PTN-bh tersebut masuk paling tidak dalam 500 besar dunia.

Sistem manajemen riset memberikan kontribusi penting untuk semua metode pemeringkatan perguruan tinggi. Kriteria kinerja riset yang diukur meliputi jumlah publikasi, sitasi dan penilaian reputasinya. Kinerja manajemen riset dipengaruhi oleh prasyarat transformasi. Enam dari 13 sistem pemeringkatan seluruhnya berfokus pada kinerja riset dengan bobot $76 \%$ dari total peringkat merupakan atribut indikator riset dan 24\% merupakan atribut indikator akademik atau kualitas pengajaran (Vernon et al. 2018). Pemeringkatan versi Quacquarelli Symonds World University Rankings (QS WUR) mengukur kinerja riset berdasarkan kriteria jumlah publikasi per dosen dengan bobot $20 \%$ dan penilaian reputasi memiliki bobot $40 \%$. Sementara itu, pemeringkatan versi Times Higher Education World University Rankings (THE WUR), bobot kriteria riset yang diukur dari survei reputasi, pendapatan dari riset, dan produktivitas sebesar 30\% dan bobot sitasinya sebesar $30 \%$ pula. Academic Rankings of World Universities (ARWU) menetapkan kriteria riset diukur berdasarkan kriteria prestasi peneliti (jumlah artikel peneliti yang disitasi) berbobot $20 \%$, publikasi di Nature and Science dengan bobot $20 \%$ dan jumlah artikel di jurnal bereputasi memiliki bobot $20 \%$.

Karakteristik WCU menurut Salmi (2009) dapat diselaraskan melalui tiga elemen kunci yaitu: (a) konsentrasi bakat dosen dan mahasiswa yang tinggi, (b) sumber daya melimpah, serta (c) tata kelola organisasi yang baik. Konsentrasi dosen dan mahasiswa yang tinggi dapat diartikan dalam segi jumlah, rasio dan kompetensi dosen sesuai bidang ilmunya. Studi kasus pada pendidikan tinggi di Pakistan mengidentifikasi faktor utama dalam transformasi pendidikan tinggi menuju internasionalisasi antara lain pengetahuan dan keterampilan, kolaborasi dan kemitraan dengan universitas internasional (Qureshi et al. 2014). Sumber daya dapat diartikan SDM riset, infrastruktur riset, insentif, dan anggaran riset. Tata kelola organisasi merupakan unsur dari sistem manajemen riset. Sistem dan manajemen riset, kultur/budaya akademik serta kepemimpinan merupakan hal-hal yang diperlukan dalam tata kelola organisasi yang baik untuk menuju perguruan tinggi status WCU.

Prasyarat transformasi sistem manajemen riset perguruan tinggi menuju WCU dapat dianalisis menggunakan Biplot. Analisis Biplot telah digunakan pada beberapa penelitian di perguruan tinggi. TorresSalinas et al. (2013) meneliti penggunaan analisis biplot untuk bibliometric multivariate dan indikator ilmiah. Penelitian Gunarto (2016) mengidentifikasi 68 perguruan tinggi swasta (PTS) dan 267 program studi di Palembang berdasarkan bentuk perguruan tinggi, yaitu Universitas dan Politeknik, Sekolah Tinggi, dan Akademi.

Sehubungan dengan pentingnya kinerja riset perguruan tinggi di Indonesia untuk menuju status World Class University (WCU), maka penelitian ini bertujuan mengidentifikasi prasyarat (enabler factors) transformasi organisasi yang efektif untuk menuju perguruan tinggi dengan kinerja riset berkualitas global. Infrastruktur riset, anggaran riset, SDM riset, insentif, kultur/budaya akademik, sistem dan manajemen riset, kerjasama akademik dan kepemimpinan merupakan prasyarat transformasi yang efektif dalam sistem manajemen riset perguruan tinggi di Indonesia menuju status World Class University (WCU). 


\section{METODE PENELITIAN}

Penelitian dilaksanakan mulai bulan Maret sampai dengan Agustus 2020. Penelitian dilakukan pada perguruan tinggi negeri (PTN) di Indonesia yang terbagi menjadi dua jenis berdasarkan statusnya yaitu Perguruan Tinggi Negeri ber-badan Hukum (PTN-bh) dan Perguruan Tinggi Negeri tidak ber-badan Hukum (PTN Non-bh). PTN-bh terbagi lagi menjadi dua yaitu PTN-bh WCU dan PTN-bh. Riset merupakan eksplorasi dari analisis deskriptif dan kuantitatif.

Data yang digunakan terdiri dari data primer dan sekunder. Data primer berasal dari kuesioner Google Form yang disebarkan kepada responden dosen di Perguruan Tinggi Indonesia menggunakan teknik purposive sampling. Kajian literatur, studi pustaka, telaah dokumen ataupun pencarian informasi menggunakan media internet merupakan jenis data sekunder yang digunakan. Dalam rangka peningkatan kinerja riset PTN-bh WCU, juga dilakukan analisis perbedaan kinerja manajemen riset dengan referensi beberapa universitas terbaik di Asia yaitu National University of Singapore (NUS), Universiti Putra Malaysia (UPM) dan University of Malaya (UM) menggunakan data sekunder.

Data primer diambil secara purposive sampling. Data primer berasal dari kuesioner Google Form yang disebarkan kepada responden dosen di Perguruan Tinggi Indonesia. Menurut Sugiyono (2015), purposive sampling adalah teknik penentuan sampel dengan pertimbangan tertentu. Responden terbagi menjadi klaster PTN-bh WCU (UI, ITB, UGM), PTNbh (IPB, UNPAD, UNDIP, ITS, USU, UPI, UNHAS, UNAIR) dan PTN Non-bh (beberapa perguruan tinggi di Indonesia, 23 PTN) berdasarkan pemeringkatan kinerja penelitian Kemenristekdikti tahun 2016-2018 (Brodjonegoro, 2019). Pada Tabel 1 disajikan daftar responden perguruan tinggi negeri di Indonesia.

Teknik analisis data dalam penelitian ini menggunakan analisis komparasi pemetaan riset dan analisis Biplot. Analisis komparasi kriteria pemeringkatan terkait kinerja riset dilakukan telaah data pemeringkatan perguruan tinggi Indonesia menurut QS WUR tahun 2020 dan 2021. Pemetaan kinerja riset perguruan tinggi Indonesia juga dilakukan dengan cara pengumpulan data melalui penyebaran kuesioner kepada para dosen di perguruan tinggi Indonesia dan komparasi dengan data sekunder untuk universitas terbaik di Asia. Hasil identifikasi prasyarat transformasi dari kuesioner dianalisis lebih lanjut menggunakan analisis Biplot sebagai dasar rekomendasi transformasi menuju PT dengan kinerja riset berkualitas global. Metode Biplot merupakan analisis eksplorasi peubah ganda yang ditujukan untuk menyajikan data peubah ganda dalam peta dua dimensi, sehingga data mudah dilihat dan diinterpretasikan (Gabriel, 2002). Analisis Biplot berdasarkan empat cara yaitu kedekatan jarak/posisi antar, panjang vektor yang terbentuk dari setiap atribut, sudut yang terbentuk dari dua vektor atribut dan kedekatan kelompok terhadap setiap atribut (Gunarto, 2016).

Kategori prasyarat transformasi terbagi menjadi tiga yaitu prasyarat utama (essential), prasyarat penting (important) dan prasyarat penunjang (useful). Infrastruktur riset, anggaran riset, SDM riset, insentif, kultur/budaya akademik, sistem dan manajemen riset, kerjasama akademik dan kepemimpinan merupakan prasyarat untuk terjadinya transformasi yang efektif dalam sistem manajemen riset perguruan tinggi di Indonesia menuju status World Class University (WCU).

Tahapan penelitian yang dilakukan adalah pemetaan kinerja riset dan identifikasi prasyarat keberhasilan transformasi manajemen riset perguruan tinggi Indonesia yang efektif. Kemudian dilakukan penentuan tingkat kepentingan prasyarat transformasi manajemen riset yang terbagi menjadi tiga kategori yaitu utama (essential), penting (important) dan penunjang (useful). Selanjutnya diperoleh kesimpulan dan rekomendasi transformasi sistem manajemen riset perguruan tinggi di Indonesia menuju status WCU dalam hal ini berupa implikasi manajerial. Pada Gambar 1 disajikan kerangka penelitian secara lebih jelas.

\section{HASIL}

\section{Pemetaan Kinerja Riset Perguruan Tinggi}

Pemetaan kinerja riset perguruan tinggi Indonesia dilakukan dengan cara pengumpulan data melalui penyebaran kuesioner kepada para dosen/peneliti di 11 PTN-bh dan beberapa PTN Non-bh Indonesia serta studi kriteria pemeringkatan terkait kinerja riset pada data pemeringkatan perguruan tinggi di Indonesia, regional dan global. Response rate pengisian kuesioner sebesar 40 persen dari total pengiriman kuesioner 
sebanyak 622 kuesioner melalui media email, Whatsapp Group, dan Whatsapp pribadi. Pemetaan kinerja riset melalui penyebaran kuesioner secara online diperoleh responden sebanyak 246 orang. Detil jumlah responden yaitu 32 orang responden klaster PTN-bh
WCU, 152 orang klaster PTN-bh dan 62 orang klaster Non PTN-bh. Jabatan akademis responden didominasi oleh Lektor (41\%), Asisten Ahli (21\%), Lektor Kepala (18\%), Guru Besar (14\%) dan jabatan lainnya/tenaga pengajar $(6 \%)$.

Tabel 1. Kategori responden perguruan tinggi negeri di Indonesia

\begin{tabular}{|c|c|c|}
\hline $\begin{array}{l}\text { Kategori Perguruan } \\
\text { Tinggi }\end{array}$ & Nama Perguruan Tinggi & $\begin{array}{c}\text { Klaster Perguruan Tinggi berdasarkan } \\
\text { kinerja penelitian 2016-2018* }\end{array}$ \\
\hline \multirow{3}{*}{$\begin{array}{l}\text { Perguruan Tinggi } \\
\text { Negeri ber-Badan } \\
\text { Hukum berstatus } \\
\text { World Class University } \\
\text { (PTN-bh WCU) }\end{array}$} & Universitas Indonesia (UI) & \multirow{3}{*}{ Mandiri } \\
\hline & Institut Teknologi Bandung (ITB) & \\
\hline & Universitas Gadjah Mada (UGM) & \\
\hline \multirow{8}{*}{$\begin{array}{l}\text { Perguruan Tinggi } \\
\text { ber-Badan Hukum } \\
\text { (PTN-bh) }\end{array}$} & Institut Pertanian Bogor (IPB) & \multirow{31}{*}{ Utama - Mandiri } \\
\hline & Universitas Padjajaran (UNPAD) & \\
\hline & Universitas Diponegoro (UNDIP) & \\
\hline & Institut Teknologi Sepuluh Nopember (ITS) & \\
\hline & Universitas Sumatera Utara (USU) & \\
\hline & Universitas Pendidikan Indonesia (UPI) & \\
\hline & Universitas Hasanuddin (UNHAS) & \\
\hline & Universitas Airlangga (UNAIR) & \\
\hline \multirow{23}{*}{$\begin{array}{l}\text { Perguruan Tinggi } \\
\text { Negeri tidak ber- } \\
\text { Badan Hukum (PTN } \\
\text { Non-bh) }\end{array}$} & Universitas Brawijaya (UB) & \\
\hline & Universitas Sebelas Maret (UNS) & \\
\hline & Universitas Riau (UNRI) & \\
\hline & Universitas Andalas (UNAND) & \\
\hline & Universitas Jambi (UNJA) & \\
\hline & Universitas Jenderal Soedirman (UNSOED) & \\
\hline & Universitas Khairun (UNKHAIR) & \\
\hline & Universitas Lambung Mangkurat (ULM) & \\
\hline & Universitas Lampung (UNILA) & \\
\hline & Universitas Malikussaleh (UNIMAL) & \\
\hline & Universitas Maritim Raja Ali Haji (UMRAH) & \\
\hline & Universitas Mataram (UNRAM) & \\
\hline & Universitas Mulawarman (UNMUL) & \\
\hline & Universitas Negeri Jakarta (UNJ) & \\
\hline & Universitas Negeri Malang (UM) & \\
\hline & Universitas Papua (UNIPA) & \\
\hline & Universitas Negeri Semarang (UNNES) & \\
\hline & Universitas Pattimura (UNPATTI) & \\
\hline & Universitas Sriwijaya (UNSRI) & \\
\hline & Universitas Tadulako (UNTAD) & \\
\hline & Universitas Tanjungpura (UNTAN) & \\
\hline & Universitas Udayana (UNUD) & \\
\hline & Universitas Sultan Ageng Tirtayasa (UNTIRTA) & \\
\hline
\end{tabular}

Keterangan : * berdasarkan pemeringkatan Kemenristek/BRIN, diakses 18 November 2019 
Pengukuran kinerja dan kualitas riset dengan menghitung jumlah publikasi dan sitasi merupakan metode paling umum untuk menilai kinerja riset perguruan tinggi (Hazelkorn, 2013). Pemetaan riset dalam Research and Development (R\&D), inovasi dan produktivitas yang dilakukan dalam studi akademis menggunakan kombinasi teknik bibliometrik dan sitasi (Broström dan Karlsson, 2017). Hasil penelitian pemetaan bibliometrik di Tata Institute of Fundamental Research (TIFR), Mumbai India selama kurun waktu tahun 2001-2015, menunjukkan produktivitas penelitian dilihat dari jumlah publikasi, jenis dokumen, sitasi, sumber jurnal, lembaga dan negara yang berkolaborasi serta lembaga pemberi dana penelitian (Kumar, 2018).

Identifikasi pemetaan kinerja riset perguruan tinggi Indonesia (Gambar 2) memperlihatkan jumlah publikasi perguruan tinggi Indonesia terindeks Scopus periode tahun 2016-2020 (SINTA, 2020). Secara keseluruhan, Universitas Indonesia tetap menduduki posisi teratas dalam hal jumlah publikasi terindeks Scopus dan Google Scholar. Berdasarkan pemeringkatan kinerja penelitian tahun 2016-2018, PTN-bh WCU dan PTNbh masuk ke dalam klaster mandiri (Brodjonegoro, 2019).

Analisis keterkaitan kinerja riset pada PT di Indonesia berdasarkan hasil pemeringkatan QS World University Ranking tahun 2020 dan 2021 dengan kriteria jumlah publikasi ilmiah Scopus, sitasi Scopus, jumlah dokumen Google Scholar dan sitasi Google Scholar. Data tersebut disajikan pada Tabel 2. Tabel 2 mengindikasikan bahwa perguruan tinggi (PT) dengan peringkat kurang dari 500 top dunia memiliki lebih banyak publikasi ilmiah terindeks Scopus, dokumen di Google Scholar dan sitasi tinggi. UI, ITB dan UGM termasuk dalam peringkat kurang dari 500 dunia dan hal ini mendasari kebijakan pemerintah bahwa PTN-bh Indonesia menuju World Class University diharapkan masuk peringkat 500 dunia.

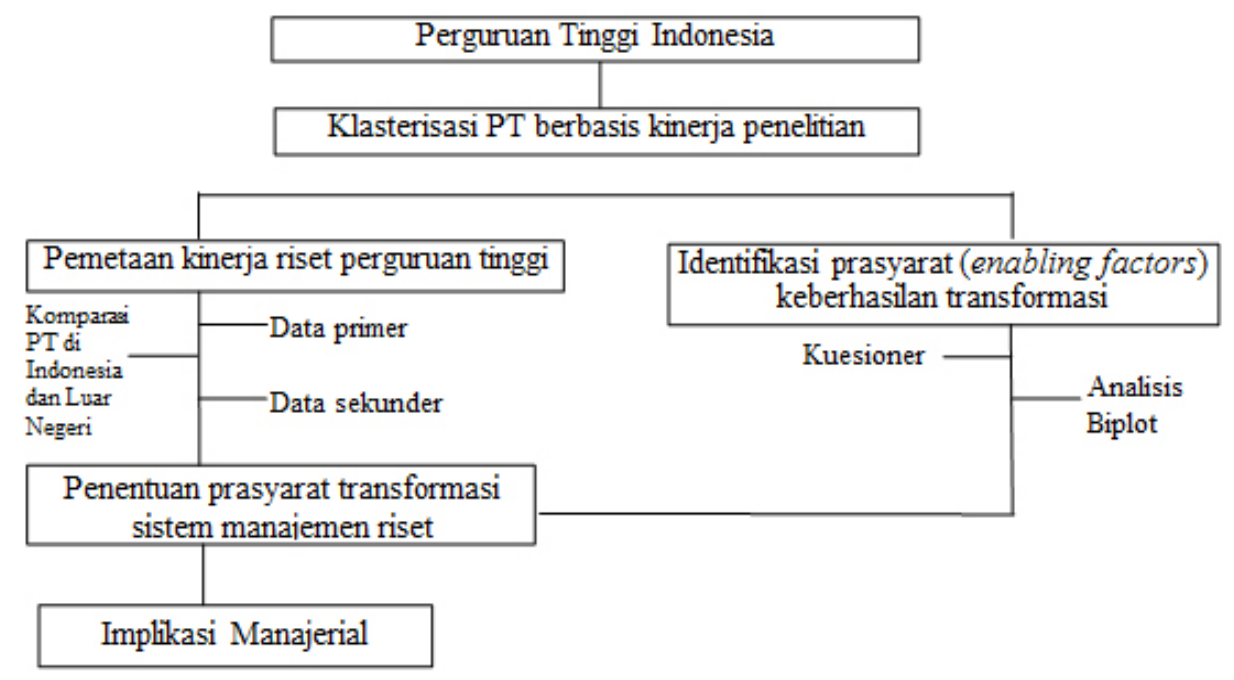

Gambar 1. Kerangka pemikiran penelitian

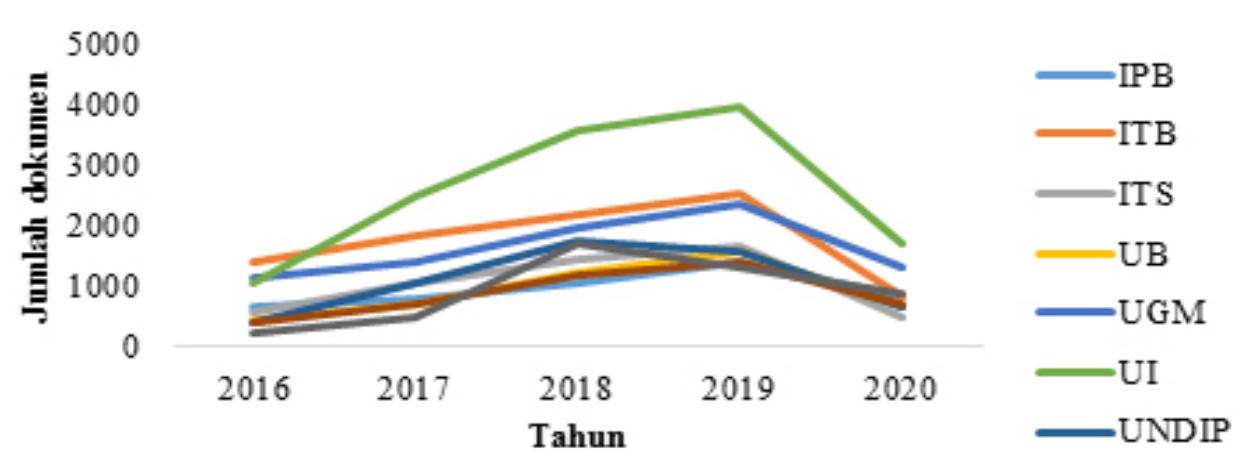

Gambar 2. Publikasi terindeks Scopus perguruan tinggi Indonesia (2016-2020) (SINTA, 2020) 
Program WCU Kementerian Riset, Teknologi dan Pendidikan Tinggi telah dimulai sejak tahun 2015. Berdasarkan data SINTA (2020), dilakukan evaluasi kinerja riset terhadap 101 perguruan tinggi Indonesia terhadap tiga PTN-bh WCU, delapan PTN-bh dan 19 PTN Non-bh dalam kurun waktu lima tahun terakhir (2015-2019) (Tabel 3 dan 4). Indikator kinerja publikasi berupa jumlah dokumen terindeks Scopus, sitasi terindeks Scopus, publikasi/dosen, dan sitasi/dosen (SINTA, 2020). Kinerja publikasi perguruan tinggi Indonesia 5 tahun terakhir tahun 2015-2019 disajikan pada Tabel 3. PTN-bh WCU memiliki kinerja riset tertinggi dalam hal publikasi dibandingkan dengan PTN-bh dan PTN Non-bh. Publikasi PTN-bh WCU dan PTN-bh tertinggi terdapat pada jurnal quartile 3 (Q3), sedangkan PTN Non-bhpada jurnal quartile 4 (Q4). Sementara itu, publikasi di quartile 1 (Q1) dan quartile $2(\mathrm{Q} 2)$ masih relatif rendah. Walaupun jumlah dosen di PTN-bh WCU besar dibandingkan dengan PT lainnya, tetapi rasio publikasi/dosen, sitasi/dosen dan paten/dosen tetap menduduki posisi tertinggi.

Tabel 2. Identifikasi kriteria pemeringkatan kinerja riset perguruan tinggi

\begin{tabular}{lcccccc}
\hline $\begin{array}{l}\text { Perguruan } \\
\text { Tinggi }\end{array}$ & $\begin{array}{c}\text { Ranking Versi } \\
\text { QS WUR Tahun } \\
2020^{*}\end{array}$ & $\begin{array}{c}\text { Ranking Versi } \\
\text { QS WUR Tahun } \\
2021^{*}\end{array}$ & $\begin{array}{c}\text { Jumlah publikasi } \\
\text { ilmiah Scopus** }\end{array}$ & $\begin{array}{c}\text { Sitasi } \\
\text { Scopus** }\end{array}$ & $\begin{array}{c}\text { Jumlah dokumen } \\
\text { Google Scholar** }\end{array}$ & $\begin{array}{c}\text { Sitasi Google } \\
\text { Scholar** }\end{array}$ \\
\hline UI & 296 & 305 & 17,372 & 144,007 & 83,696 & 815,216 \\
ITB & 331 & 331 & 15,246 & 140,077 & 60,403 & 479,641 \\
UGM & 320 & 254 & 12,459 & 119,478 & 139,813 & 610,069 \\
IPB & $601-650$ & $530-540$ & 7,848 & 80,427 & 91,411 & 625,35 \\
ITS & $801-1000$ & $751-800$ & 7,792 & 53,896 & 39,035 & 195,08 \\
UNAIR & $651-700$ & $520-530$ & 6,567 & 45,066 & 36,984 & 168,331 \\
UNPAD & $751-800$ & $801-1000$ & 5,003 & 41,869 & 52,77 & 262,647 \\
UNDIP & $801-1000$ & $801-1000$ & 6,684 & 40,209 & 83,156 & 328,782 \\
USU & $>1000$ & $>1000$ & 5,21 & 27,858 & 48,124 & 146,843 \\
UPI & $>1000$ & $>1000$ & 3,572 & 14,468 & 46,223 & 487,885 \\
UNHAS & $>1000$ & $>1000$ & 5,931 & 42,668 & 45,708 & 217,914 \\
\hline
\end{tabular}

Sumber: topuniversities (2020); SINTA (2020)

Tabel 3. Kinerja publikasi perguruan tinggi Indonesia 5 tahun terakhir (2015-2019)

\begin{tabular}{lccccccccc}
\hline \multirow{2}{*}{ Status PT } & $\begin{array}{c}\text { Dokumen } \\
\text { Scopus * }\end{array}$ & $\begin{array}{c}\text { Sitasi } \\
\text { Scopus* }\end{array}$ & \multicolumn{9}{c}{ Q1 } & Q2 & Q3 & Q4 & Tidak masuk Q & Publikasi// & $\begin{array}{c}\text { Sitasi// } \\
\text { Dosen* }\end{array}$ & \begin{tabular}{c} 
Dosen* \\
\hline PTN-bh
\end{tabular} & 9228 & 31955 & 1037 & 1161 & 2700 & 2075 & 2255 & 0,873 & 16,333 \\
WCU & & & & & & & & & \\
PTN-bh & 4673 & 14620 & 369 & 523 & 1755 & 1292 & 733 & 0,624 & 10,182 \\
PTN Non-bh & 1666 & 4521 & 114 & 176 & 517 & 568 & 290 & 0,261 & 3,732 \\
\hline
\end{tabular}

Keterangan: * data merupakan rata-rata nilai dari setiap kategori

Sumber: SINTA (2020)

Tabel 4. Kinerja paten perguruan tinggi Indonesia 5 tahun terakhir (2015-2019)

\begin{tabular}{lccc}
\hline Status PT & IPR & Paten & Paten/ dosen \\
\hline PTN-bh WCU & 1242 & 423 & 0,217 \\
PTN-bh & 618 & 218 & 0,142 \\
PTN Non-bh & 489 & 84 & 0,061 \\
\hline
\end{tabular}

Keterangan: rata-rata nilai dari setiap kategori

Sumber: SINTA (2020) 
Hasil tersebut menunjukkan bahwa jumlah publikasi terindeks Scopus pada perguruan tinggi di Indonesia selamalimatahunterakhirmengalamitrenkenaikan. Tren publikasi ilmiah pada jurnal bereputasi dibandingkan dengan publikasi pada prosiding internasional juga mengalami peningkatan. Hal ini menandakan bahwa para dosen semakin menyadari pentingnya kualitas riset yaitu mempublikasikan hasil risetnya di jurnal ilmiah dibandingkan dengan prosiding. Selain itu, juga berdampak lebih besar pada penilaian kinerja dosen. Semakin bertambahnya publikasi ilmiah bereputasi internasional pada perguruan tinggi Indonesia baik dari segi kuantitas dan kualitas, menunjukkan semakin pentingnya status World Class University sebagai bentuk pengakuan dan reputasi perguruan tinggi secara global. Transformasi perguruan tinggi menuju World Class University melalui internasionalisasi perguruan tinggi dalam rangka merespon tuntutan globalisasi (Zulfa, 2012). Indikator kinerja paten terdiri dari jumlah
Intellectual Property Rights (IPR), jumlah paten dan paten/dosen. Pada Tabel 4 disajikan data kinerja paten perguruan tinggi pada klaster PTN-bh WCU, PTNbh dan PTN Non-bh di Indonesia dalam jangka lima tahun terakhir (tahun 2015-2019). PTN-bh WCU juga memiliki kinerja paten tertinggi dibandingkan PTN lainnya.

Analisis komparasi perguruan tinggi Indonesia(Tabel 5) dilakukan pada universitas terbaik di Asia yaitu National University of Singapore (NUS) sebagai peringkat pertama (top $50 \mathrm{WCU}$ ), University of Malaya sebagai peringkat ke-13 (top $100 \mathrm{WCU}$ ) dan Universiti Putra Malaysia (UPM) menduduki peringkat ke-33 terbaik di Asia (top 200, WCU) (Quacquarelli Symonds, 2020a). Kriteria pemetaan riset terdiri dari peringkat/ranking, jumlah publikasi terindeks scopus, jumlah sitasi, sitasi per dosen, sitasi per paper, international research network index, pendanaan riset dan SDM periset.

Tabel 5. Perbandingan kinerja riset PT Indonesia dengan NUS, UM, dan UPM

\begin{tabular}{|c|c|c|c|c|c|c|}
\hline Kriteria & Non PTN-bh & PTN-bh & PTN-bh WCU & $\begin{array}{c}\text { Top } 50 \text { WCU } \\
\text { (NUS) }\end{array}$ & $\begin{array}{c}\text { Top } 100 \\
\text { WCU (UM) }\end{array}$ & $\begin{array}{c}\text { Top } 200 \\
\text { WCU (UPM) }\end{array}$ \\
\hline Rankingl) & $\begin{array}{c}>1000, \text { QS } \\
\text { Stars Rating } \\
\text { System } 3\end{array}$ & $500-1000$ & $<500$ & 11 & 59 & 132 \\
\hline $\begin{array}{l}\text { Jumlah publikasi } \\
\text { terindeks scopus } \\
\text { 2,3) }\end{array}$ & $3.643^{2)}$ & $6.890^{2)}$ & $15.090^{2)}$ & $66.542^{3)}$ & $26.300^{3)}$ & $20.877^{3)}$ \\
\hline Jumlah sitasi²,3) & $18.703^{2)}$ & $52.095^{2)}$ & $136.222^{2)}$ & $2.545 .313^{3)}$ & $233.092^{3)}$ & $250.447^{3)}$ \\
\hline Sitasi per dosen ${ }^{1,2)}$ & $3,7^{2)}$ & $10,2^{2)}$ & $16,3^{2)}$ & $72,9^{1)}$ & $47,7^{1)}$ & $22,3^{1)}$ \\
\hline Publikasi per dosen ${ }^{2)}$ & $0,26^{2)}$ & $0,62^{2)}$ & $0,87^{2)}$ & $14^{1)}$ & $11^{1)}$ & $9^{1)}$ \\
\hline $\begin{array}{l}\text { International research } \\
\text { network index }{ }^{1)}\end{array}$ & $\mathrm{N} / \mathrm{A}^{*}$ & 33 & 59 & 100 & 100 & 99,8 \\
\hline $\begin{array}{l}\text { Pendanaan riset 2018- } \\
2019\end{array}$ & $\mathrm{Rp} 26.4 \mathrm{M}^{\mathrm{a}}$ & $\operatorname{Rp} 86.6 \mathrm{M}^{\mathrm{b})}$ & $\mathrm{Rp} 104.41 \mathrm{M}^{\mathrm{c})}$ & $\begin{array}{l}\text { USD } 758.12 \\
\text { Million }^{\mathrm{d})}\end{array}$ & $\begin{array}{l}\text { RM } 73 \\
\text { million }^{\text {e) }}\end{array}$ & $\begin{array}{l}\text { RM } 65 \\
\text { million }^{\mathrm{f}}\end{array}$ \\
\hline SDM periset $^{1)}$ & 1.650 & 2.417 & 3.643 & 12.176 & 5.769 & 5.801 \\
\hline
\end{tabular}

Keterangan: $* \mathrm{~N} / \mathrm{A}=$ data tidak tersedia

Sumber data: ${ }^{1)}$ Www.topuniversities.com, diakses 19 Agustus 2020; ${ }^{2)}$ SINTA, diakses 20 Agustus 2020; ${ }^{3}$ Laporan

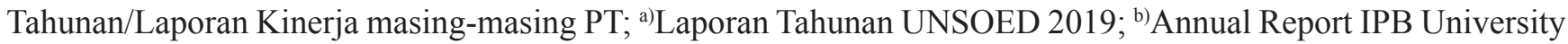

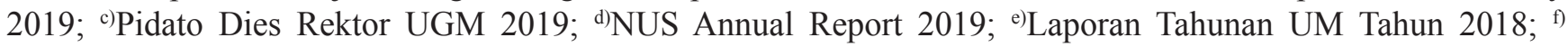
Prospectus UPM Tahun 2020-2021 
Nilai yang diperoleh pada Tabel 5 merupakan nilai ratarata lima PT untuk PTN Non-bh dan PTN-bh, dan tiga PT untuk PTN-bh WCU pada setiap kategori. Klaster PTN Non-bh terdiri dari UB, UNS, UNAND, UNSOED dan UNJ), klaster PTN-bh terdiri dari IPB, ITS, UNAIR, UNDIP, UNPAD dan klaster PTN-bh WCU terdiri dari UI, UGM dan ITB. Hasil penelitian analisis komparasi pemetaan menunjukkan bahwa NUS, UM dan UPM mempunyai kinerja riset yang sangat tinggi. Kinerja riset tersebut antara lain memiliki jumlah dokumen Scopus dan sitasi yang tinggi, anggaran riset besar, SDM periset banyak, fasilitas lengkap dan jumlah mahasiswa internasional besar. Sementara itu, kinerja riset perguruan tinggi di Indonesia umumnya masih berada pada posisi medium - high, walaupun ITB kinerja risetnya very high namun jumlah mahasiswa internasional masih kurang (Quacquarelli Symonds, 2020b).

Persepsi responden terhadap parameter kinerja riset perguruan tinggi pada klaster PTN-bh WCU, PTN-bh dan PTN Non-bh disajikan pada Tabel 6 dengan rentang nilai 1-5, dimana nilai 1 menandakan tidak penting dan sebaliknya nilai 5 menandakan sangat penting. Prasyarat transformasi diidentifikasi berdasarkan respon dosen dari tiga klaster perguruan tinggi Indonesia. Salah satu indikator prasyarat terjadinya transformasi manajemen riset yang efektif menuju status WCU adalah adanya dukungan riset antar peneliti. Dukungan riset antar peneliti (peer support) berupa seringnya interaksi antara dosen senior dengan dosen muda dan kolaborasi riset antar peneliti pada ke-3 klaster PT Indonesia penting untuk meningkatkan produktivitas riset. Hasil penelitian (Tabel 6) memperlihatkan bahwa rata-rata indikator kinerja riset pada ketiga klaster perguruan tinggi memiliki nilai di atas 4 (sangat penting). Secara umum, rata-rata indikator kinerja tersebut sangat penting, tetapi yang masuk ke dalam kategori sangat penting adalah budaya mutu untuk ketiga PTN. Indikator yang mendekati nilai maksimum adalah budaya mutu yang dimiliki dan sudah diterapkan dengan baik di ketiga klaster PTN. Implementasi budaya mutu dan budaya kerja di perguruan tinggi merupakan kombinasi dari dimensi konten, konteks dan proses yang penting untuk menuju perubahan organisasi yang lebih baik. Dimensi konten, konteks dan proses merupakan prasyarat yang berdampak positif pada implementasi perubahan organisasi (Cheng, 2015).

Namun demikian pada Tabel 6, apabila dilihat dari masing-masing indikator, nilai terkecil kurang dari 4 (cukup penting) dimiliki oleh PTN-bh WCU dan PTNbh untuk indikator keterbukaan proses seleksi. Hal ini menandakan bahwa indikator keterbukaan proses seleksi, derajat kepentingannya lebih rendah untuk PTN-bh WCU, PTN-bh dan PTN Non-bh namun tidak terlalu memengaruhi kinerja riset. Nilai rendah pada klaster PTN Non-bh terdapat pada indikator dukungan infrastruktur sehingga perlu lebih ditingkatkan. Hal yang sama juga terjadi di Mesir, dimana perguruan tinggi negeri yang akan menuju status WCU menghadapi beberapa tantangan antara lain bahasa, penelitian, infrastruktur dan model tata kelola (Ahmed, 2015). Sebagai perbandingan, beberapa infrastruktur riset yang dimiliki oleh NUS, UM dan UPM antara lain berupa pusat unggulan (center of excellence) dengan kelompok riset/klaster keilmuan yang unggul serta sarana laboratorium yang lengkap dan memadai. Selain itu, NUS, UM dan UPM juga memiliki banyak SDM periset berkompeten dan dana riset yang besar (Tabel $5)$.

Tabel 6. Indikator kinerja riset perguruan tinggi Indonesia berdasarkan persepsi responden

\begin{tabular}{lccc}
\hline Indikator & PTN-bh WCU & PTN-bh & Non PTN-bh \\
\hline Dukungan riset antar peneliti & 4,34 & 4,20 & 4,10 \\
Kolaborasi riset & 3,88 & 4,12 & 4,23 \\
Dukungan infrastruktur & 3,89 & 3,69 & 3,46 \\
Keterbukaan proses seleksi & 3,61 & 3,75 & 3,48 \\
Kebijakan dan pengelolaan riset dan publikasi & 4,06 & 3,96 & 3,92 \\
Budaya mutu & 4,69 & 4,79 & 4,71 \\
Budaya kerja & 4,41 & 4,62 & 4,52 \\
Kualitas riset & 4,03 & 4,32 & 4,37 \\
Kuantitas riset & 4,47 & 4,57 & 4,55 \\
Dampak riset & 4,28 & 4,45 & 4,53 \\
Rata-rata & 4,17 & 4,25 & 4,19 \\
\hline
\end{tabular}


Knowledge management (KM) merupakan salah satu komponen dalam infrastruktur riset. PTN-bh WCU dan PTN-bh memiliki nilai indikator dukungan infrastruktur riset lebih tinggi dibanding PTN Non-bh karena PTN-bh telah melakukan implementasi KM dengan baik. Empat PTN-bh teratas di Indonesia (UI, ITB, UGM dan IPB) telah memiliki infrastruktur dasar pelaksanaan KM yang baik dimana pihak manajemen telah berpartisipasi secara aktif dalam promosi inisiatif KM dengan mengartikulasikan strategi KM, menyediakan alokasi anggaran dan sistem penghargaan (Nur et al. 2017). Penerapan knowledge management (KM) didukung oleh empat prasyarat (kepemimpinan, budaya, teknologi informasi dan pengukuran kinerja) menjadi penting di universitas negeri di Malaysia (Ramachandran et al. 2013). Pengelolaan organisasi dan SDM juga merupakan bagian dari infrastruktur riset. Organisasi, SDM dan keterampilan merupakan prasyarat untuk eksekusi suatu strategi organisasi (Leibbrandt dan Botha, 2014).

\section{Prasyarat Keberhasilan Transformasi}

Hasil penelitian mengindentifikasi kategori tingkat kepentingan prasyarat keberhasilan transformasi yaitu prasyarat utama (essential), prasyarat penting (important) dan prasyarat penunjang (useful) (Tabel 7). Pada semua PTN, infrastruktur riset merupakan prasyarat utama (essential) dalam meningkatkan kinerja riset. Kerjasama akademik dan kepemimpinan teridentifikasi sebagai prasyarat penunjang pada PTN.

Menurut Direktorat Jenderal Komisi Riset Eropa, infrastruktur riset merupakan fasilitas, sumber daya, dan layanan terkait yang digunakan oleh komunitas ilmiah untuk melakukan penelitian di bidangnya masing-masing. Infrastruktur riset dapat mencakup peralatan atau seperangkat instrumen; sumber daya berbasis pengetahuan seperti koleksi, arsip, publikasi ilmiah; infrastruktur berbasis teknologi informasi dan komunikasi sepertijaringan, komputasi, perangkat lunak dan komunikasi, atau entitas lain yang bersifat unik yang penting untuk mencapai keunggulan penelitian (European Commission, 2010). Peran infrastruktur riset menjadi bagian dari sebuah ekosistem yang terhubung membentuk sumber daya untuk penelitian dan analisis interdisipliner ilmiah yang kompleks. Infrastruktur riset adalah investasi utama dalam riset pada semua bidang ilmu, dimana menuntut adanya sumber daya yang memadai untuk mendukung pengembangan ilmu dan transfer pengetahuan untuk inovasi di bidang sosial dan ekonomi (ESFRI, 2018).

Sejalan dengan penelitian Nguyen dan Klopper (2014), produktivitas penelitian sangat dipengaruhi oleh iklim akademik, sumber daya dan insentif. Dalam penelitian ini, sumberdaya yang dimaksud adalah anggaran riset, infrastruktur riset dan SDM riset. Anggaran riset menjadi prasyarat penting pada semua PT, walaupun pemerintah memberikan tambahan anggaran riset sesuai dengan pemeringkatan top universitas dunia, tetapi dosen menganggap anggaran riset tersebut masih kurang apabila luaran yang diharapkan publikasi pada jurnal bereputasi internasional. Anggaran riset dan insentif/reward sebagai prasyarat penting pada PTN-bh karena dalam meningkatkan kinerja riset, para dosen juga memerlukan insentif/reward dari institusi berupa tambahan dana riset dan publikasi atau tambahan remunerasi. Dengan adanya insentif ini, para dosen diharapkan akan semakin giat meneliti. Pada PTN Non-bh, SDM riset merupakan prasyarat penting dalam meningkatkan kinerja risetnya. Kultur/budaya akademik dan sistem manajemen riset merupakan prasyarat penting (important) dan sudah menjadi keseharian dalam kehidupan akademik dosen PTNbh WCU. Budaya akademik adalah budaya atau sikap hidup yang selalu mencari kebenaran ilmiah melalui kegiatan akademik dalam masyarakat akademik, yang mengembangkan kebebasan berpikir, keterbukaan, pikiran kritis-analitis, rasional dan objektif oleh warga masyarakat yang akademik (Tosepu, 2018). Salah satu ciri budaya akademik adalah budaya meneliti, membaca dan menulis menjadi ciri khas PTN-bh WCU. Terbukti bahwa PTN-bh WCU mempunyai jumlah dokumen terindeks Scopus dengan sitasi yang tinggi sehingga masuk dalam peringkat 500 top universitas dunia.

\section{Analisis Biplot}

Analisis Biplot memberikan penegasan prasyarat terjadinya transformasi manajemen riset perguruan tinggi Indonesia menuju status WCU (Gambar 3). Analisis Biplot dapat melihat posisi dan jenis perguruan tinggi Indonesia merujuk kepada prasyarat transformasi manajemen riset. Hasil analisis dapat dilihat berdasarkan panjang vektor variabel prasyarat yang terbentuk menunjukkan keragaman nilai antar objek (jenis PT), dimana semakin panjang vektor maka semakin berbeda nilainya. Hasil analisis Biplot juga dapat diintrepretasikan berdasarkan arah variabel 
terhadap objek dimana semakin dekat arah variabel ke suatu objek maka nilai variabel pada objek tersebut relatif lebih besar daripada objek lainnya.

Infrastruktur riset merupakan prasyarat utama bagi ketiga klaster perguruan tinggi berdasarkan hasil analisis lebih lanjut dengan Biplot. Berdasarkan panjang vektor yang terbentuk dari setiap prasyarat menunjukkan keragaman data. Infrastruktur riset dengan vektor panjang, dan paling besar nilainya, dianggap prasyarat utama oleh semua PTN. Berdasarkan panjang vektor, terlihat bahwa tingkat kepentingan/derajat keutamaan infrastruktur riset pada PTN Non-bh lebih tinggi dibanding PTN-bh dan PTN-bh WCU. Semakin PT tersebut mengarah kepada status WCU, tingkat kebutuhan akan infrastruktur relatif lebih kecil. Hasil analisis Biplot pada PTN Non-bh menunjukkan bahwa derajat keutamaan infrastruktur riset lebih tinggi diikuti SDM riset dan kerjasama akademik. PTN-bh memiliki derajat keutamaan anggaran riset dan insentif yang lebih besar. Lain halnya dengan PTN-bh WCU, dimana derajat keutamaan prasyarat kultur/budaya akademik dan sistem manajemen riset lebih tinggi.

Tabel 7. Tingkat kepentingan prasyarat keberhasilan transformasi

\begin{tabular}{llll}
\hline Tingkat kepentingan & PTN-bh WCU & PTN-bh & Non PTN-bh \\
\hline Prasyarat utama (essential) & Infrastruktur riset & Infrastruktur riset & Infrastruktur riset \\
Prasyarat penting (important) & Kultur/budaya akademik & Anggaran riset & SDM riset \\
& $\begin{array}{l}\text { Sistem dan manajemen } \\
\text { riset }\end{array}$ & Insentif & Anggaran riset \\
& Anggaran riset & SDM riset & Sistem dan manajemen riset \\
& Insentif & Kultur/budaya akademik & Insentif \\
& SDM riset & Sistem dan manajemen & Kultur/budaya akademik \\
& & riset & \\
Prasyarat penunjang $($ useful) & Kerjasama akademik & Kerjasama akademik & Kerjasama akademik \\
& Kepemimpinan & Kepemimpinan & Kepemimpinan \\
\hline
\end{tabular}

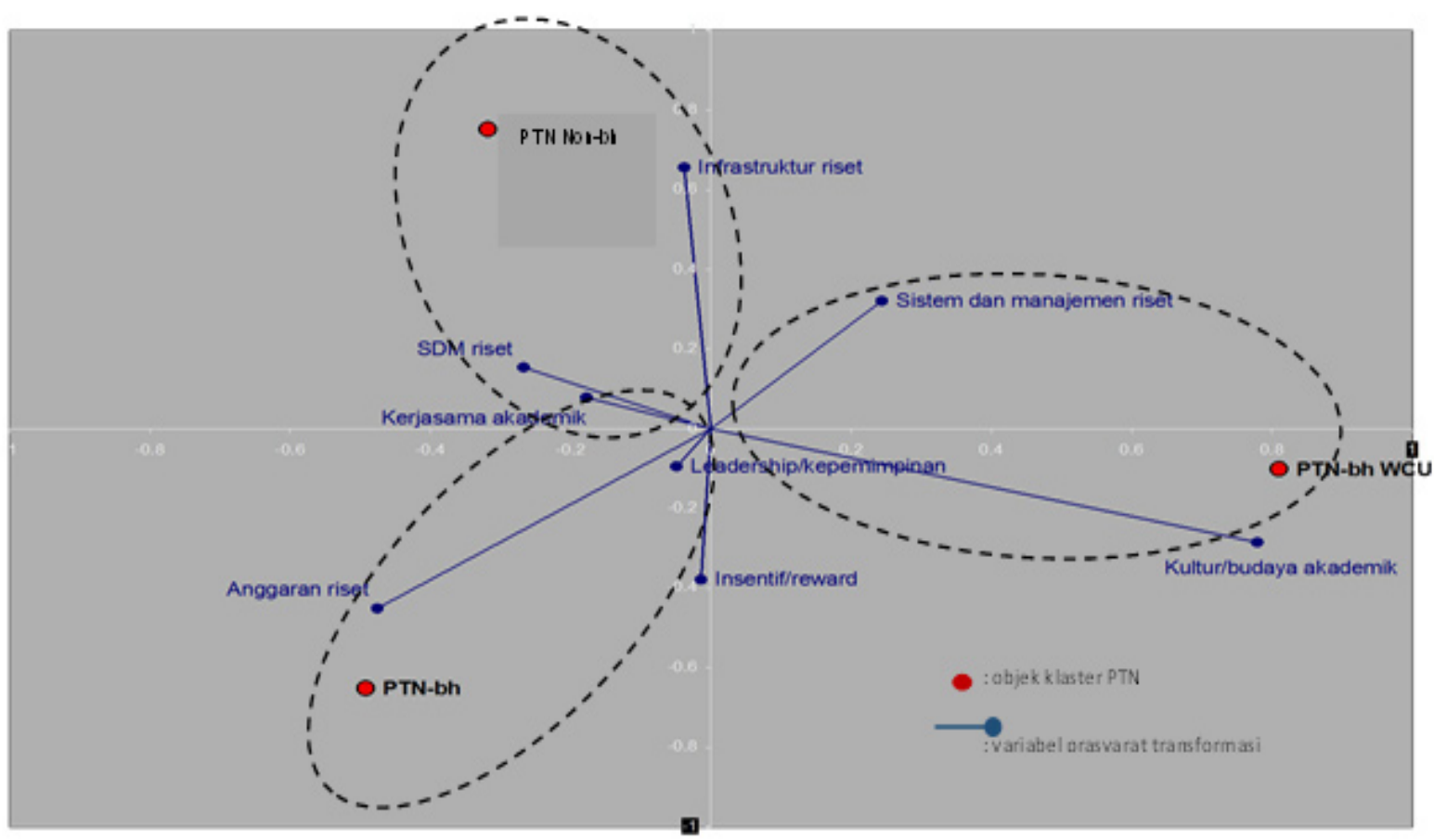

Gambar 3. Hasil analisis biplot antara objek jenis perguruan tinggi dengan variabel prasyarat transformasi sistem manajemen riset 
Data persepsi responden kemudian dianalisis menggunakan Biplot juga mempertegas prasyarat penting pada klaster perguruan tinggi sesuai dengan hasil penelitian (Tabel 7). Produktivitas kerjasama penelitian yang berkelanjutan, faktor manajemen riset dan knowledge management (KM) merupakan prasyarat yang penting (Johnsson, 2017). Pada PTN-bh WCU, kultur/budaya akademik dan sistem manajemen riset merupakan prasyarat penting. Anggaran riset dan insentif merupakan prasyarat penting bagi PTNbh, sedangkan SDM riset dan kerjasama akademik merupakan prasyarat penting bagi Non PTN-bh. Kerjasama akademik pada PTN Non-bh perlu mendapatkan perhatian khusus walaupun termasuk dalam kategori penunjang. Hal ini dikarenakan pada Non PTN-bh, kerjasama akademik yang terjalin relatif masih lebih sedikit dibandingkan dengan PTN-bh dan PTN Non-bh terutama poin international research network index berdasarkan hasil pemeringkatan $Q S$ Asia University Rankings (Tabel 2).

Efek dari pemeringkatan universitas berkelas global, pemerintah menggunakan peringkat ini untuk mengklasifikasikan, mengakreditasi perguruan tinggi, mengalokasikan sumber daya, mendorong perubahan, menilai hasil belajar dan pembelajaran siswa dan/atau mengevaluasi kinerja dan produktivitas riset institusi di tingkat nasional. Produktivitas penelitian juga dikaitkan dengan kekayaan intelektual dan ekonomi suatu negara. Kesamaan berbasis negara dalam profil produktivitas penelitian juga tampaknya dipengaruhi oleh kedekatan geografis (Jaffe et al. 2020). Toutkoushian dan Webber (2011), pentingnya analisis produktivitas penelitian suatu lembaga terkait dengan fakta bahwa produksi pengetahuan otentik penting bagi perkembangan sosial ekonomi bangsa dan negara. Produktivitas penelitian tidak hanya diukur berdasarkan jumlah publikasi namun juga dampak dari penelitian tersebut (Vernon et al. 2018).

Sejalan dengan hasil kajian sebelumnya, bahwa prasyarat transformasi manajemen riset menuju status WCU memerlukan prasyarat utama, penting dan penunjang. Infrastruktur riset merupakan prasyarat utama bagi semua PT dalam bertransformasi menuju status WCU. Proses transformasi manajemen riset perguruan tinggi Indonesia bagi PTN Non-bh menjadi PTN-bh memerlukan infrastruktur riset, SDM riset dan kerja sama akademik. PTN-bh untuk menuju status PTN-bh WCU dalam melakukan transformasi manajemen riset memerlukan pendanaan riset dan insentif berupa penghargaan untuk para peneliti. Transformasi PTN-bh WCU menuju status top world class university lebih memerlukan kultur/budaya akademik dan sistem manajemen riset. yang mengarah pada kolaborasi riset internasional serta kualitas publikasi bereputasi internasional.

\section{Implikasi Manajerial}

Beberapa hal yang direkomendasikan untuk PTN Nonbh dalam meningkatkan kinerja riset perguruan tinggi menuju WCU yaitu perlunya peningkatan infrastruktur riset berupa sarana laboratorium, sarana teknologi informasi dan perpustakaan yang lebih memadai. Di samping itu, PTN Non-bh perlu meningkatkan kualitas SDM riset dan kerjasama akademik. Peningkatan anggaran dana riset, dana publikasi internasional dengan impact factor tinggi, serta penambahan insentif sebagai penghargaan bagi periset diperlukan oleh PTN-bh. Penguatan budaya/iklim akademik dan sistem manajemen riset dipelukan oleh PTN-bh WCU.

\section{KESIMPULAN DAN SARAN}

\section{Kesimpulan}

Simpulan dari hasil penelitian ini yaitu ketiga klaster responden menghasilkan luaran penelitian (jumlah publikasi dan sitasi) yang berbeda, dan PTN-bh WCU menghasilkan jumlah publikasi dan sitasi tertinggi. Namun masih jauh di bawah NUS, UPM dan UM. Penyediaan infrastruktur penelitian yang memadai merupakan prasyarat utama (essential) bagi semua PTN Indonesia. Anggaran riset, SDM riset, insentif, sistem dan manajemen riset serta budaya akademik merupakan prasyarat penting untuk transformasi manajemen riset perguruan tinggi. Sementara itu, prasyarat penunjang transformasi manajemen riset yang teridentifikasi dalam penelitian adalah kerjasama akademik dan kepemimpinan. Hasil analisis biplot juga mempertegas bahwa penyediaan infrastruktur riset yang memadai sebagai prasyarat utama (essential enabler) bagi semua perguruan tinggi. Prasyarat penting yang secara spesifik memengaruhi kinerja riset juga ditunjukkan oleh hasil Biplot yaitu PTN Non-bh (SDM riset, kerjasama akademik), PTN-bh (pendanaan riset, insentif) dan PTN-bh WCU (budaya akademik, sistem dan manajemen riset). 


\section{Saran}

Saranuntukpenelitian selanjutnya, perlumemperhatikan prasyarat transformasi lainnya, memperluas lingkup objek penelitian dan perumusan strategi perlu divalidasi dengan focus group discussion (FGD) atau brainstrorming dan in-depth interview dengan para pemangku kebijakan riset baik pada level pimpinan PT dan pemerintah (Kemendikbud dan Kemenristek/ BRIN).

\section{UCAPAN TERIMA KASIH}

Terima kasih disampaikan kepada Kementerian Riset, Teknologi dan Pendidikan Tinggi dan Kementerian Pendidikan dan Kebudayaan yang telah memberikan Beasiswa Tenaga Kependidikan Berprestasi (PaSTi) tahun 2018.

\section{DAFTAR PUSTAKA}

Ahmed HOK. 2015. Strategic approach for developing world-class universities in egypt. Journal of Education and Practice 6(5):246-288.

Brodjonegoro BPS. 2019. Evaluasi dan Klasterisasi Perguruan Tinggi Berbasis Kinerja Penelitian 2019. Jakarta: Kementerian Riset dan Teknologi/ Badan Riset dan Inovasi Nasional.

Broström A, Karlsson S. 2017. Mapping research on R\&D, innovation and productivity: a study of an academic endeavour. Economics of Innovation and New Technology. 26 (1-2):6-20. http:// dx.doi.org/10.1080/10438599.2016.1202519.

Cheng L. 2015. Enablers that positively impact implementation of organizational change. GSTF Journal on Business Review 4(1):5-10. http:// dx.doi.org/10.5176/2010-4804.

ESFRI. 2018. Roadmap \& strategy report on Research Infrastructure. http://roadmap2018.esfri.eu/ media/ 1048/rm2018-part1-20.pdf [2020 Nov $6]$.

European Commission. 2010. What is a Research Infrastructure? RISCAPE. doi:10.2777/79873. https://blogs.helsinki.fi/riscape-project/what-isa-research-infrastructure [2020 Nov 6].

Gabriel KR. 2002. Goodness of fit of biplots and correspondence analysis. Biometrika. 89(2):423436. http://dx.doi.org/10.1093/biomet/89.2.423. Gunarto M. 2016. Analysis on the Positioning of Private
Higher Education Institutions Based on Fields of Science. Di dalam: $1^{\text {st }}$ UPI International Conference on Sociology Education (UPI ICSE 2015). Atlantis Press. hlm. 313-316. https:// papers.ssrn.com/sol3/papers.cfm?abstract id $=3179597$ [2020 Feb 11].

Hazelkorn E. 2013. World-Class Universities or WorldClass Systems? Rankings and Higher Education Policy Choices. UNESCO Forum on Rankings and Accountability in Higher Education. (May):1-23.

[IPB] Institut Pertanian Bogor. 2019. Annual Report $I P B$ University 2019. Bogor: Institut Pertanian Bogor.

Jaffe K, ter Horst E, Gunn LH, Zambrano JD, Molina G. 2020. Anetwork analysis of research productivity by country, discipline, and wealth. PLoS One 15(5):1-15. doi:10.1371/journal.pone.0232458.

Jarocka M. 2015. Transparency of university rankings in the effective management of university. Business, Management and Education 13(1):6475. http://dx.doi.org/10.3846/ bme.2015.260.

Johnsson M. 2017. Innovation enablers for innovation teams - a review. Journal of Innovation Management 5(3):75-121. http://dx.doi. org/10.24840/2183-0606_005.003_0006.

[Kemenristekdikti]. Kementerian Riset, Teknologi dan Pendidikan Tinggi. 2019. Arah dan kebijakan riset nasional. Dirjen Penguatan Riset dan Pengembangan. 12 Juli 2019: Bogor. IPB International Convention Center.

Kumar S. 2018. Bibliometric mapping of research productivity of TIFR Mumbai as seen through the mirror of Web of Science. Library Philosophy and Practice. 2018 (May): 1-20.

Leibbrandt J, Botha C. 2014. Organization, people and skills as an enabler for strategy execution in municipalities in South Africa. International Business \& Economics Research Journal (IBER). 14(1):15-26. http://dx.doi.org/10.19030/iber. v14i1.9028.

Nguyen QH, Klopper JC. 2014. The influences of research environment within a university on research productivity of academic staff-A case study in a research-oriented university in Vietnam. International Journal of Arts and Sciences 7(2):189-197.

Nur RNN, Fauzi AM, Sukoco H. 2017. Strategies of knowledge management implementation for academic services improvement of indonesian higher education. Journal of Information and 
Knowledge Management. 16(4):1-23. http:// dx.doi.org/10.1142/S0219649217500320.

[NUS] National University of Singapore. 2019. Passion Forward Annual Report 2019. Singapore (SG) : National University of Singapore. https://www. nus.edu.sg/docs/default-source/annual-report/ nus-annualreport-2019.pdf [2020 Agu 19].

Quacquarelli Symonds. 2020a. QS World University Rankings and QS Asia University Rankings. QS World Univ Rank QS Asia Univ Rank 2020. https://www.topuniversities.com/ universityrankings/asian-university-rankings/2020 [internet]. [2020 Feb 26].

Quacquarelli Symonds. 2020b. QS World University Rankings and QS Asia University Rankings. QS World Univ Rank QS Asia Univ Rank 2021. https://www.topuniversities.com/universityrankings/asian-university-rankings/2021 [2020 Des 15].

Qureshi MI, Janjua SY,Zaman K, Lodhi MS, TariqY Bin. 2014. Internationalization of higher education institutions: Implementation of DMAIC cycle. Scientometrics. 98(3):2295-2310. doi:10.1007/ s11192-013-1163-9.

Ramachandran DS, Chong SC, Wong KY. 2013. Knowledge management practices and enablers in public universities: A gap analysis. CampusWide Information Systems. 30(2):76-94. http:// dx.doi.org/10.1108/10650741311306273.

[SINTA] Science and Technology Index, Indonesia Kementerian Riset dan Teknologi/Badan Riset dan Inovasi Nasional. 2020. Data publikasi perguruantinggi Indonesia.http://sinta.ristekbrin. go.id/. [2020 Jun 21 dan 2020 Agu 29].

Sugiyono. 2015. Metode Penelitian Pendidikan (Pendekatan Kuantitatif, Kualitatif dan R\&D). Bandung: Alfabeta.

Tambunan MR, Anwar R. 2019. Transformasi budaya organisasi otoritas perpajakan indonesia menghadapi era ekonomi digital. Jurnal Aplikasi Manajemen dan Bisnis. 5(2):253-264. http:// dx.doi.org/10.17358/jabm.5.2.253.
Torres-Salinas, Jiménez-Contreras DNR-G and E, Herrera F, López-Cózar ED. 2013. On the use of biplot analysis for multivariate bibliometric and scientific indicators. Journal of the American Society for Information Science and Technology. 64(July):1-12. http://dx.doi.org/10.1002/asi.

Toutkoushian RK, Webber K. 2011. Measuring The Research Performance of Postsecondary Institutions. Di dalam: Shin JC, Toutkoushian RK, Teichler U, editor. University Rankings, The Changing Academy - The Changing Academic Profession in International Comparative Perspective 3. Springer Science + Business Media B.V. hlm. 123-144.

[UGM] Universitas Gadjah Mada. 2019. Laporan Tahunan Rektor Tahun 2019. Yogyakarta: Universitas Gadjah Mada. https://simpan.ugm. ac.id/s/MYarnqZKXONtunQ\#pdfviewer [2020 Agu 21].

[UM] University of Malaya. 2018. Laporan Tahunan UM 2018. Malaysia: University of Malaya. https://www.um.edu.my/LTUM18\%20061119. pdf [2020 Agu 21].

[UNSOED] Universitas Jenderal Soedirman. 2019. Laporan Tahunan Rektor Dies Natalis Ke56 Tahun 2019. Purwokerto: Universitas Jenderal Soedirman. https://drive.google. com/file/d/1 g M A 8s 7eTORQCt9u2R ek9eFmS3E6EYfo/view?usp=sharing $\quad[2020$ Agu 21].

[UPM] Universiti Putra Malaysia. 2020. Prospectus 2020-2021. Malaysia : Universiti Putra Malaysia. https://coscomm.upm.edu.my/upload/dokum en/20200715154447Prospectus_UPM_20202021_FullBook.pdf [2020 Agu19].

Vernon MM, Balas AE, Momani S. 2018. Are university rankings useful to improve research? A systematic review. PLoS One. 13(3):1-15. http://dx.doi.org/10.1371/journal.pone.0193762.

ZulfaU.2012.Transformasiinternasionalisasiperguruan tinggi menuju world class university. LITERASI (Jurnal Ilmu Pendidikan). 3(1):111-124. http:// dx.doi.org/10.21927/literasi.2012.3(1).111-124. 